\title{
In Hospital Morbidity and Mortality of Chronic Renal Disease in a Country where Access to Dialysis is Limited
}

\author{
BAH Alpha Oumar ${ }^{1 *}$, Diallo Thierno Abdoulaye ${ }^{1}$, Balde Mamadou Cellou ${ }^{2}$, BAH Kadiatou-Hadiatou ${ }^{1}$, Kimso Oumou ${ }^{1}$ and $^{2}$ Lionel Rostaing $^{3}$
}

${ }^{1}$ Department of Pathology, Academic Medical Center, University of Amsterdam, Amsterdam, Netherlands

${ }^{2}$ Department of Pathology, Radboud University Nijmegen Center, Nijmegen, Netherlands

${ }^{3}$ Department of Nephrology, Renal Transplantation, CHU Rangueil University, Toulouse, France

\begin{abstract}
In this study, we sought to investigate the morbidity and mortality due to chronic renal failure (CRF) in a hospital with very limited access to renal replacement therapy. We did a retrospective study conducted at the Department of Nephrology at Donka National Hospital in Conakry (Guinea) over a period of 6 years, from January 1 st 2006 to December 31st, 2011. Were included into the study, all patients hospitalized in the ward for chronic renal failure whose records were complete; 484 records ( $\mathrm{H} 56.40 \% \mathrm{~F} 43.60 \%$ ) were used. The average age was of $41.9 \pm 15.17$ years (1580 years). Three hundred and thirty-seven patients $(69.63 \%)$ were under educated. Housewives and workers accounted for $55.60 \%$ of the population. Renal failure was moderate in $14 \%$, severe in $21 \%$ and renal failure in $65 \%$. Proteinuria was positive in 359 patients. Probable causes were chronic glomerulonephritis (37.8\%), vascular nephropathy (31.2\%), interstitial nephropathy $(9.9 \%)$, diabetic nephropathy $(7.4 \%)$, a HIVAN $(3.3 \%)$, polycystic kidney disease $(1.9 \%)$; the nephropathy was undetermined in $8.5 \%$ of cases. The risk factors for renal disease were hypertension in 371 cases (76.65\%), consumption of nephrotoxic drugs in 328 cases $(67.76 \%)$, smoking in 99 cases $(12.39 \%)$ and diabetes in 51 cases $(10.5 \%)$. Only 315 patients underwent hemodialysis; $20 \%$ died. Among the causes of death: anemia, heart failure, HIV, pericarditis, and stroke were statistically significant.
\end{abstract}

Keywords: Chronic renal disease; Morbidity; Mortality; Conakry

\section{Introduction}

Chronic kidney disease (CKD) is a major public health issue; due to its constant increase in incidence and prevalence, and the high cost of replacement therapy. People with CKD develop cardiovascular disease more often than the general population. They can also develop renal failure. At this stage, dialysis or kidney transplantation (which are extremely expensive) are required [1,2]. The epidemiology of renal failure is very different in sub-Saharan Africa where the budget allocated to health is low compared to developed countries. Moreover, in these countries, renal disease preferentially affects economically active young subjects, and its actual extent is unknown. Early detection can be effective in developed countries, but it is problematic in developing countries such as the Republic of Guinea where patients are always seen at a terminal stage. The mortality of chronic renal failure patients is affected by a combination of socio-economic factors, preexisting medical disorders, comorbidity treatment modalities and renal failure itself

The objective of the present study was to determine the morbidity and mortality due to the CKD in a hospital where access to renal replacement therapy is very limited. The aim was to determine the frequency, identify causes, risk factors of CKD, and to determine the frequency and causes related to these deaths.

\section{Material and Methods}

This is a retrospective observational cohort study done in the only Nephrology Service of Guinea, located in Conakry. The ward accommodates 15 beds. Six years of data were collected from January $1^{\text {st }}, 2006$ to December 31 $1^{\text {st }}, 2011$.

The study population consisted of patients hospitalized during the study period. Were admitted into the study all patients hospitalized for renal insufficiency. Patients with acute renal disease, CKD outpatients and patients with incomplete records were excluded. Chronic renal failure was defined as a creatinine clearance $<60$ $\mathrm{ml} / \mathrm{min}$ (MDRD) with signs of chronic anemia, hypocalcemia, small kidneys, and cortico-medullary dedifferentiation. The level of education was said to be low for patients who have only primary level education, average for high school level, and high for university level education.

Data collection was based on:

- Risk factors for renal disease: hypertension, diabetes, HIV, urinary infections, nephrotoxic drugs, tobacco, alcohol, history of proteinuria and hematuria

- Complications of renal failure

- Associated pathologies

- Lab results on entry and during hospital stay

The statistical analyzes focused on the description of the population, the comparison of characteristics of patients who died and those who did not, the mortality estimation and risk factors analysis for death. Quantitative variables were presented as mean \pm standard deviation or median and qualitative variables were presented in percentages. Comparisons of quantitative variables were made by the Student test and qualitative ones Fisher test.

\section{Results}

During the study period, 1,578 patients were hospitalized; of which 906 were cases of chronic kidney failure, a hospitalization frequency

*Corresponding author: BAH Alpha Oumar, Head of the Department, Department of Nephrology, Donka National Hospital, BP 234, Conakry, Guinea, Tel: +224 622218375; E-mail: bahalphaoumar1@gmail.com

Received December 19, 2014; Accepted March 04, 2015; Published March 09, 2015

Citation: BAH, Abdoulaye DT, Cellou BM, Kadiatou-Hadiatou BAH, Oumou K, et al. (2015) In Hospital Morbidity and Mortality of Chronic Renal Disease in a Country where Access to Dialysis is Limited. J Nephrol Ther 5: 195. doi: 10.4172/2161-0959.1000195

Copyright: (c) $2015 \mathrm{BAH}$, et al. This is an open-access article distributed under the terms of the Creative Commons Attribution License, which permits unrestricted use, distribution, and reproduction in any medium, provided the original author and source are credited. 
Citation: BAH, Abdoulaye DT, Cellou BM, Kadiatou-Hadiatou BAH, Oumou K,et al. (2015) In Hospital Morbidity and Mortality of Chronic Renal Disease in a Country where Access to Dialysis is Limited. J Nephrol Ther 5: 195. doi:10.4172/2161-0959.1000195

Page 2 of 3

of $57.42 \%$; 484 records were selected. There were 273 men $(56.40 \%)$ and 211 women $(43.60 \%)$. Ages 15 to 80 with a mean of $41.9 \pm 15.7$ years; $94.8 \%$ of patients were younger than 70 years of age. Three hundred thirty-seven patients $(69.63 \%)$ had a low level on education, $78(16.11 \%)$ had a high school education and $69(14.26 \%)$ had a university level education. In terms of occupation, housewives and workers represented $55.60 \%$ (269) of our study population. The risk factors for renal disease were hypertension in 371 cases $(76.65 \%)$, use of nephrotoxic drugs in 328 cases (67.76\%), smoking in 99 cases (12.39\%) and diabetes in 51 cases (10.5\%). Of the 296 patients who had an electrocardiogram done, 183 cases of coronary heart disease were noted. Pericardial friction was noted in 16 patients. 121 fundus exams were done, 57 had stage III and IV retinopathies. In terms of chronicity, 434 patients $(89.66 \%)$ had a hemoglobin level $<10$ g; $445(91.94 \%)$ had hypocalcemia; 422 (87.6\%) had small kidneys, 53 (10.96\%) had normal kidney size and $7(1.44 \%)$ had increased kidney size. Proteinuria was positive in 359 patients of which 17 had proteinuria greater than 3 $\mathrm{g} / 24 \mathrm{~h}$. Renal insufficiency was moderate in 68 cases $(14 \%)$, severe in 101 cases (21\%) and kidney disease in 315 cases (65\%). Probable causes were, chronic glomerulonephritis in 183 patients (37.8\%), vascular nephropathy in 151 patients $(31.2 \%)$, interstitial nephropathy in 48 patients (9.9\%), diabetic nephropathy in 36 patients (7.4\%), HIV in 16 patients (3.3\%) out of the 27 cases of HIV positive patients (mainly of type 1), polycystic kidney in 9 patients (1.9\%) and in 41 cases $(8.5 \%)$, nephropathy was undetermined. The average length of hospital stay was $13.97 \pm 8.18$ days. Only 315 patients had benefited from hemodialysis; 97 deaths were recorded (20\%), including 68 in the last stage renal disease; among them, 85 were undereducated. Nineteen left without consent $(3.9 \%)$. Among the causes of death, anemia $(p=0.0008)$, heart failure $(p=0.00000001), \operatorname{HIV}(p=0.000021)$, pericarditis $(p=0.000027)$, and stroke $(\mathrm{p}=0.0038)$ were statistically significant (Tables $1-4)$.

\section{Discussion}

This retrospective study, conducted over a period of 6 years, showed that the incidence of CKD was of $57.42 \%$, representing an annual increase of $4 \%$ in the same service [3]. This alarming increase was probably related to the significant increase in major risk factors (hypertension, diabetes, improper use of nephrotoxic drugs) and also to the lack of early screening for kidney disease. In Africa, the prevalence

\begin{tabular}{|c|c|c|}
\hline & HIVAN+ & HIVAN- \\
\hline \multicolumn{3}{|c|}{ Profession } \\
\hline Housewives & 3 & 3 \\
\hline Workers & 8 & 2 \\
\hline Marchant & 1 & 1 \\
\hline Civil servants & 3 & 2 \\
\hline Students & 1 & 1 \\
\hline Man in Uniforms & 0 & 2 \\
\hline \multicolumn{3}{|c|}{$p=0,49719018 ;$ Chi-square $=2,38$} \\
\hline \multicolumn{3}{|c|}{ Age } \\
\hline 29-Oct & 4 & 1 \\
\hline $30-49$ & 5 & 3 \\
\hline $50-69$ & 7 & 6 \\
\hline $70-89$ & 0 & 1 \\
\hline \multicolumn{3}{|c|}{$P=0,66355864 ;$ Chi-square $=1,58 ; \mathrm{ddl}=3$} \\
\hline \multicolumn{3}{|c|}{ Sex } \\
\hline M & 8 & 3 \\
\hline $\mathrm{F}$ & 8 & 8 \\
\hline \multicolumn{3}{|c|}{$P=0,2376251 ;$ Chi-square $=1,39 ; d d l=1$} \\
\hline
\end{tabular}

Table 1: Demographic Studies of HIV

\begin{tabular}{|c|c|c|c|}
\hline & HIVAN+ & HIVAN- & p \\
\hline Age & 16 & 11 & 0,66355864 \\
\hline Sex & 16 & 11 & 0,2376251 \\
\hline Profession & 16 & 11 & 0,49719018 \\
\hline
\end{tabular}

Table 2: Total Mean values on Demographic Studies.

\begin{tabular}{|c|c|c|}
\hline & DECEASED & ALIVE \\
\hline \multicolumn{3}{|c|}{ Anemia } \\
\hline YES & 78 & 356 \\
\hline NO & 19 & 31 \\
\hline \multicolumn{3}{|c|}{$p=0,0008082 ;$ Chi-square $=11,22 ; d d l=1$} \\
\hline \multicolumn{3}{|c|}{ Cardiac failure } \\
\hline Yes & 81 & 206 \\
\hline NO & 16 & 181 \\
\hline \multicolumn{3}{|c|}{$p=0,0000001 ;$ Chi-square $=29,45 ; d d l=1$} \\
\hline \multicolumn{3}{|l|}{ HIV } \\
\hline YES & 9 & 7 \\
\hline NO & 88 & 380 \\
\hline \multicolumn{3}{|c|}{$p=0,0002338 ;$ Chi-square $=13,54$} \\
\hline
\end{tabular}

Table 3: Effect of Diseases on Morbidity and Mortality.

\begin{tabular}{|c|c|c|c|}
\hline & DECEASED & ALIVE & $\mathbf{p}$ \\
\hline Anemia & 78 & 356 & 0,0008082 \\
\hline Cardiac failure & 81 & 206 & 0,0000001 \\
\hline HIV & 9 & 7 & 0,0002338 \\
\hline
\end{tabular}

Table 4: Total Mean Values on Morbidity and Mortality

of CKD is 4-5 times higher than in developed countries [4].

Several studies have provided consistent data on the susceptibility of the black man to develop chronic kidney disease [4,5]. The average age of our patients was of $41.9 \pm 16$ years, the same as everywhere in Africa, Dakar [6], Nigeria [4] and the Congo [7]; contrary to the United States of America where the average age of patients with kidney disease was of 65 years [8].

This difference is explained by the aging of the population but also by the early diagnosis and appropriate care which slows the evolution towards kidney failure. The sex ratio was 1:29; this male preponderance is consistent with literature and may be related to the higher incidence of renal disease in man and their more rapid progression to renal failure [1]. Two thirds of our patients had low levels education, risk factor in developing CKD [7]. They were mainly housewives, workers and merchants; their low socio-economic status made access to quality care difficult and consequently leading to the use of traditional medicine. Risk factors were dominated by hypertension, nephrotoxic drugs, smoking and diabetes. In Morocco, the main risk factors were hypertension and diabetes [8] as well as in the United States, Japan, Australia and Europe [1]. The majority of our patients were not admitted early on, which illustrates the high proportion of uremic poisoning just like in most African countries where the signs were dominated by hypertension, vomiting and anemia; this is contrary to the developed countries, where hypertension was the only sign due to early treatment [9]. Probable etiologies encountered in our series were arranged according to frequency: glomerular nephropathy (37.8\%), vascular nephropathy (31.2\%), interstitial nephropathy (9.9\%), diabetic nephropathy $(7.4 \%)$, the HIV-associated nephropathy (3.3\%), and polycystic kidney disease (1.9\%); nephropathy was undetermined in $8.5 \%$ of cases. Our results were similar to those recorded in 2009 in Kinshasa by Sumaili [7]. The prognosis of CKD was severe in our series, anemia, vomiting, malnutrition, and cardiovascular disease had a negative impact on 
Citation: BAH, Abdoulaye DT, Cellou BM, Kadiatou-Hadiatou BAH, Oumou K,et al. (2015) In Hospital Morbidity and Mortality of Chronic Renal Disease in a Country where Access to Dialysis is Limited. J Nephrol Ther 5: 195. doi:10.4172/2161-0959.1000195

the quality of life of our patients; although $65 \%$ of our patients were supposed to receive dialysis, only $16 \%$ had been admitted because of the insufficient number of machines, which explains the high mortality rate. The main causes of death were anemia $(\mathrm{p}=0.0008)$, heart failure ( $\mathrm{p}=0.00000001)$, HIV $(\mathrm{p}=0.0002338)$, pericarditis $(\mathrm{p}=0.000027)$, and stroke $(\mathrm{p}=0.0038)$; they were statistically significant. This high mortality rate should motivate policy makers to subsidize kidney disease care.

\section{Conclusion}

Renal failure prevalence is at an increase and mainly touches economically active young people. The etiologies were chronic glomerulonephritis and hypertension. The lack of early detection, the delay in diagnosis and the inability to adequately treat CKD, explain the high morbidity and mortality rates associated with chronic renal failure. This should challenge the government and non-governmental organizations to create health insurance policies and subsidize treatment centers for kidney failure. It is urgent to establish prevention and early detection program for kidney disease in our country.

\section{Reference}

1. Claire PN, Emmanuel V (2001) Epidémiologie et étiologie de l'Insuffisance Rénale Chronique; Revue du praticien [article in French] 51: 365-371.
2. Stevens LA, Coresh J, Feldman HI, Greene T, Lash JP, et al. (2007) Evaluation of the modification of diet in renal disease study equation in a large diverse population. J Am Soc Nephrol 18: 2749-2757.

3. Bah AO, Kaba ML, Diallo MB, Kake A, Balde MC, et al. (2006) Morbidité et mortalité hospitalières dans le service de Néphrologie de l'hôpital national Donka. Mali médical [article in French] T XXI: 42-46.

4. Arogundade FA, Sanusi AA, Hassan MO, Akinsola A (2011) The pattern, clinical characteristics and outcome of ESRD in lle-lfe, Nigeria: is there a change in trend? Afr Health Sci 11: 594-601.

5. Naicker S (2009) End-Stage disease in Sub-Saharan Africa. Ethn Dis 19: S113-5.

6. Toure IY (1984) Place de la néphrologie dans la morbidité dans un service de médecine interne pour adultes noirs africains à Dakar ; à propos de 379 cas. Dakar Médical [article in French] 29: 213-220.

7. Sumaili EK, Krzesinski JM, Cohen EP, Nseka NM (2010) Epidémiologie de la Maladie Rénale Chronique en République Démocratique du Congo : une revue synthétique des études de Kinshasa, la capitale. Néphrologie et Thérapeutique [article in French] 6: 232-239.

8. Dennai $Y$ (2012) Prise en charge de l'insuffisance rénale terminale en urgence (à propos de 140 cas) : thèse de doctorat, Université de Casablanca, Maroc [Thesis in French].

9. Jungers P, Robino C, Choukroun G (2001) Evolution de l'épidémiologie de l'insuffisance rénale chronique et prévision des besoins en dialyse de suppléance en France. Néphrologie 22: 91-97. 